\title{
Inhibitors of protein aggregates as novel drugs in neurodegenerative diseases
}

\author{
Pietrobono D, Giacomelli C, Trincavelli ML*, Daniele $\mathrm{S}^{*}$ and Martini C \\ Department of Pharmacy, University of Pisa, Pisa, Italy
}

\begin{abstract}
Neurodegenerative diseases commonly present misfolding and aggregation of one or more proteins, including primarily $\beta$-Amyloid, $\alpha$-synuclein and tau. Over the last decades, several efforts have been made to understand the molecular processes at the basis of such pathological aggregation, as well as in the development of therapeutic strategies targeting these diseases. Among these, the inhibition of protein aggregation with natural compounds, peptides or small molecules has been considered a promising pharmacological approach. Here in, the most promising molecules developed to reduce protein aggregation will be summarised and discussed on the light of their effects in pre-clinical and clinical studies.
\end{abstract}

\section{Introduction}

Neurodegenerative diseases (NDs) are characterised by the misfolding and aggregation of specific proteins [1]. For example, the pathological hallmarks of Alzheimer's disease are represented by $\beta$-Amyloid $(A \beta)$ peptide-containing plaques and intraneuronal neurofibrillary tangles composed of hyperphosphorylated protein tau. Meanwhile, Parkinson's disease (PDs) presents brain inclusions of $\alpha$-synuclein ( $\alpha$-syn), which constitutes the major component of Lewy bodies and Lewy neurites [2-4]. Such pathological protein aggregation relates to a complex self-assembly process involving the formation of small oligomers, larger protein complexes, and mature $\beta$-sheetrich fibrils. Whether prefibrillar aggregates (oligomers, protofibrils) or fibrils are accountable for neuronal death in NDs remains to be established [1,5].

Different therapeutic strategies attempting to reduce brain burden of protein aggregates have been developed [5] including: i) direct targeting of misfolded proteins; ii) drawing the protein excess out of the brain by peripheral administration of oligomer-binding agents (the so-called "sink effect") [6-8]; iii) upregulating molecular chaperones or proteins involved in aggregate clearance [5]; iv) targeting posttranslational modifications that promote protein misfolding and aggregation [5]; v) the use of nanotechnological devices, and in particular multifunctional liposomes $[9,10]$. Herein, current literature on compounds able to prevent/disrupt protein aggregation, thus removing toxic oligomers, will be summarised [11].

\section{a-Syn aggregation inhibitors}

The a-syn oligomerization inhibitors have been deeply investigated (Table 1). Among synthetic compounds able to counteract $\alpha$-syn oligomerization in preclinical studies, NPT200-11 [12] and ANLE138b $[13,14]$ are rising as promising tool for the PD treatment. In particular, NPT200-11 has been shown to cross the blood-brain barrier with low toxicity in control subjects, completing successfully a phase I clinical trial (ClinicalTrials.gov Identifier NCT02606682).

Small peptides able to control oligomerization have been developed as $\beta$-sheet breakers, taking into account that the aggregation site involves the 71-82 region of $\alpha$-syn. In this respect, unmodified peptides [15] and N-methylated peptides [16] have been recently discovered and demonstrated their efficacy in vitro. Studies are ongoing to collect clinical data and additional information on the use of peptide able to induce a correct protein folding $[17,18]$.

Among natural-based compounds, polyphenols such as baicalin [19], EGCG [20,21], tannic acid (TA) [22], resveratrol [23] and curcumin [24] have been emerging as potent molecules able to decrease $\alpha$-syn assembling into oligomers. However, almost all the studies on these compounds are limited to the pre-clinical phase.

Another pharmacological approach is represented by active or passive immunization based on a-syn antibodies [25]. Such immunogenic peptides mimic the C-terminus of $\alpha$-syn [26], or can direct bind the oligomeric form of $\alpha$-syn, or the Ser 129 phosphorylated site of $\alpha$-syn [27], which is a crucial site for $\alpha$-syn accumulation [28].

\section{Tau aggregation inhibitor}

Tau aggregates have been targeted using several approaches, which have been reviewed elsewhere [29,30]. In the last decade, different classes of tau aggregation inhibitors (TAIs) have been reported, including polyphenols [31], porphyrins [32], phenothiazines such as Methylene blue [32], benzothiazoles/cyanines such as N744 and Riluzole [33], thioxothiazolidinones (rhodanines), phenylthiazolehydrazides, anthraquinones, and aminothienopyridazines (ATPZs) $[30,33]$ (Table 2).

Furthermore, small molecules belonging to TAIs have already been developed and tested in humans $[29,34,35]$, even if with discrepancy

Correspondence to: Simona Daniele and Maria Letizia Trincavelli, Department of Pharmacy, University of Pisa, Via Bonanno 6, Pisa, Italy, E-mail: simona. daniele@for.unipi.it; maria.trincavelli@unipi.it

Received: February 02, 2017; Accepted: February 20, 2017; Published: February 24,2017 
Table 1. Structures of the main $\alpha$-syn aggregate inhibitors.

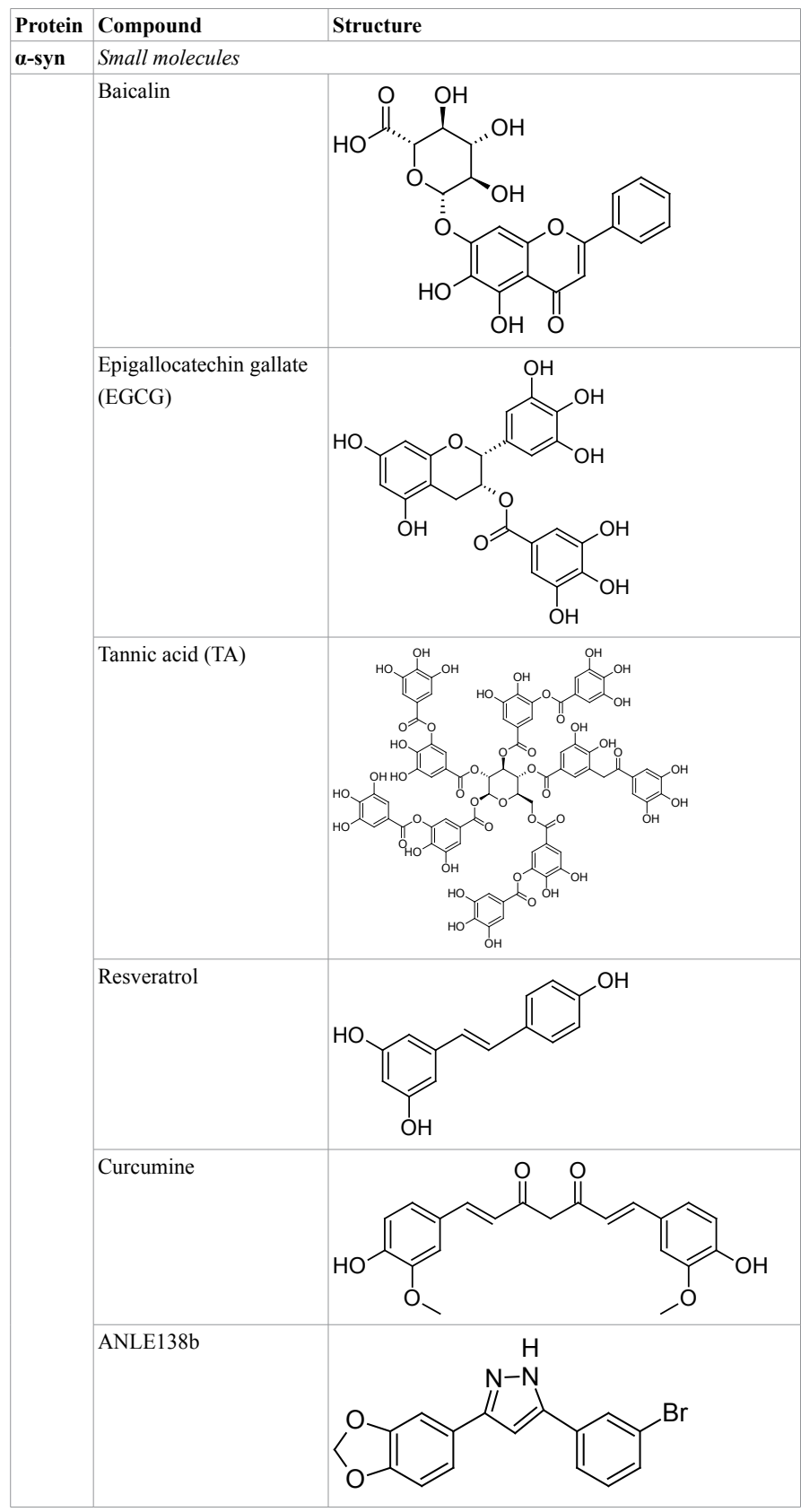

between the cell-based and/or in vitro data and the in vivo efficacy. Important pharmaceutical implications have been rising from the possibility to distinguish the tau-tau binding interaction from the tautubulin binding one with new aggregation inhibitors [36,37]. Among these, the most promising compound is leucomethylthioninium (LMT, leucomethylene blue (MB), LMTX, TRx0237), developed by TauRxTherapeutics Ltd., Republic of Singapore, which is a secondgeneration TAI for AD treatment. The numerous clinical trials that are currently ongoing for this compound and its derivatives (ClinicalTrials. gov Identifier NCT01626391, NCT01689233, NCT01689246, NCT01626378, NCT02245568) are failing, probably due to the subject advanced stage of the pathology.

Several other chemical entities and compounds have been reported
Table 2. Structures of the main Tau aggregate inhibitors.

\begin{tabular}{|l|l|l|l|l|}
\hline Protein & Compound & Methylene blue \\
\hline Tau & Small molecules & Riluzole \\
TRx0237 \\
(LMT, leucomethylene \\
blue, LMTX)
\end{tabular}

[38-40]. A new compound, PE859 (3-[(1E)-2-(1H-indol-6-yl)ethenyl]5-[(1E)-2-[2-methoxy-4-(2-pyridylmethoxy)phenyl] ethenyl]-1Hpyrazole) has been shown to inhibit in vitro tau aggregation and to delay the onset and progression of motor dysfunction in vivo [38]. Moreover, 1,2-dihydroxybenzene-containing compounds have been shown to reduce tau oligomerization [39] in vitro or in vivo.

\section{$A \beta$ aggregation inhibitor}

Small derivatives have been developed that are able to interfere with $A \beta$ aggregation by decreasing the oligomerization process and/ or by inducing a conformational change in $\beta$-sheet assembly and/or by inducing quick conversion of soluble aggregates into less toxic fibrils (Table 3) [1,41].

Among natural compounds, most $A \beta$ inhibitors present a polyphenolic core [42], including resveratrol [43], myricetin [44], curcumin [45], caffeine [46].

As concern, newly synthesised compounds, ALZ-801 is an orally bioavailable prodrug of Tramiprosate, which has been demonstrated to reduce $A \beta$ oligomers and neurotoxicity.

Moreover, ALZT-OP1 results from the combination of two FDAapproved drugs, cromolyn and ibuprofen. Consequently, it decreases neuronal death by reducing $\mathrm{A} \beta$ accumulation and suppressing neuroinflammation in the brain [47].

Another interesting small molecule is CSP-1103, able to inhibit brain deposition of $\mathrm{A} \beta$ plaques, reducing tau pathology and neuroinflammation, and reversing memory deficits in $\mathrm{AD}$ transgenic mouse model. Additionally, CSP-1103 restores normal microglial function by increasing phagocytosis and decreasing production of proinflammatory cytokines.

ELND005 is an orally bioavailable inositol stereoisomer that 
Table 3. Structures of the mainA $\beta$ aggregate inhibitors.

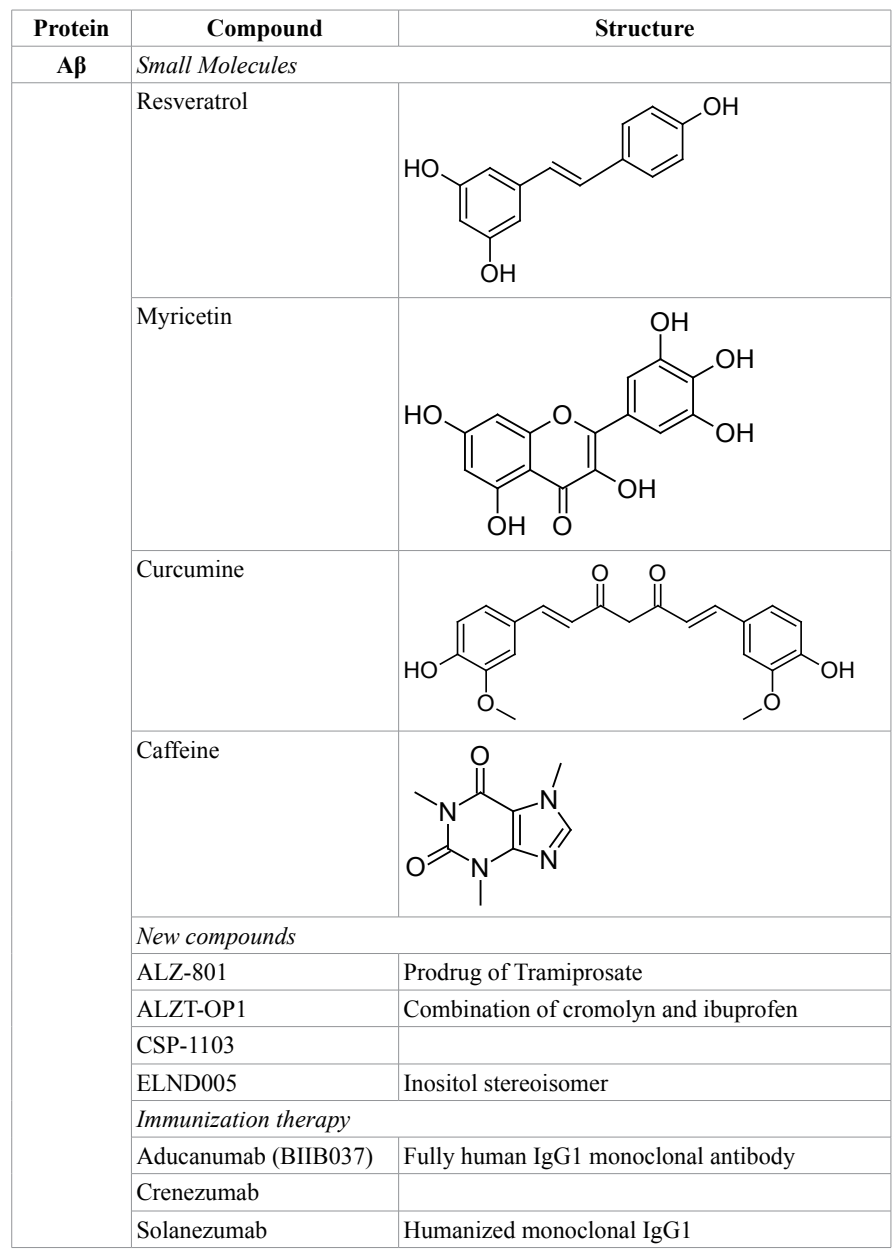

causes a dose-dependent decrease in amyloid pathology and plaque accumulation in TgCRND8 mice. The completed Phase II AD study demonstrated ELND005 treatment led to reduction in myoinositol levels in the brain, an effect that is shared by other approved neuropsychiatric drugs such as lithium and valproic acid. In addition, ELND005 has been associated with a reduction in the levels of $A \beta$ and tau proteins in the cerebrospinal fluid.

Another therapeutic approach targets the nucleation site of aggregation. This region, known as the KLVFFA, is an hexapeptide sequence that facilitates monomer-monomer interaction, leading to dimer and oligomer formation [48,49]. Based on these findings, a few compounds have been identified and demonstrated to interact with the KLVFFA region [50].

Among the $A \beta$-anti-aggregating strategies, an anti- $A \beta$ immunotherapy approach has been emerging. In particular, antibodies that recognize $A \beta$ toxic species have been developed to bind and neutralize them; otherwise, the antibodies can stimulate microglial clearance, or induce $A \beta$ exit from the brain [51-57].

Among antibodies, Aducanumab (BIIB037) is a high-affinity, fully human IgG1 monoclonal antibody against a conformational epitope found on $A \beta$, which is now in phase III trial. On the other hand, Crenezumab recognizes multiple forms of aggregated $A \beta$, including oligomeric and fibrillar species and amyloid plaques with high affinity. It has been engineered to clear $A \beta$ excess and stimulate amyloid phagocytosis while limiting release of inflammatory cytokines, as a way to avoid side effects such as vasogenic edema [53].

Finally, Solanezumab is a humanized monoclonal IgG1 antibody directed against the mid-domain of the $A \beta$ peptide, which recognizes soluble monomeric $A \beta$. It has been designed to sequester $A \beta$, shifting equilibria between different species of $\mathrm{A} \beta$, and removing small soluble species of $A \beta$ that are directly toxic to synaptic function [58].

\section{Conclusions and future perspectives}

Despite several efforts, inhibitors of $\mathrm{A} \beta$, $\alpha$-syn and tau protein deposition have failed in clinical trials. The inadequacy of the disease-modifying strategy, and the stage of the disease during the drug administration are only two of the reasons at the basis of the clinical trial failure. Indeed, several findings have suggested that the pharmacological treatment of NDs should start prior to the onset of clinical symptoms [59], and that each inhibitor may have a precise temporal window in which to be used, depending on the ND stage [1].

Drug combinations that capitalise on more than one therapeutic strategy will constitute the most effective treatment for NDs. Furthermore, the cooperation of $A \beta$, tau and $\alpha$-syn in the pathogenic processes of NDs [60-62] is opening the way to broad-spectrum compounds potentially able to reduce the oligomerization of more than one protein. Rifampicin, a well-known antibiotic, can reduce prevent the aggregation of $A \beta$, tau and $\alpha$-syn in vitro [62] and in a mouse model of AD. Future advance may be represented by the development of agents able to interfere with hybrid oligomers.

\section{References}

1. Giacomelli C, Daniele S, Martini C (2017) Potential biomarkers and nove pharmacological targets in protein aggregation-related neurodegenerative diseases. Biochem Pharmacol 2952: 30047-30053.

2. Spillantini MG, Schmidt ML, Lee VM, Trojanowski JQ, Jakes R, Goedert M (1997) Alpha-synuclein in Lewy bodies. Nature 388: 839-840.

3. Miraglia F, Betti L, Palego L, Giannaccini G (2015) Parkinson's disease and alphasynucleinopathies: from arising pathways to therapeutic challenge. Cent Nerv Syst Agents Med Chem 15: 109-116.

4. Dickson DW (2012) Parkinson's disease and parkinsonism: neuropathology. Cold Spring Harb Perspect Med 2: 2.

5. Rochet JC (2007) Novel therapeutic strategies for the treatment of protein-misfolding diseases. Expert Rev Mol Med 9: 1-34.

6. Matsuoka Y, Saito M, LaFrancois J, Saito M, Gaynor K, et al. (2003) Novel therapeutic approach for the treatment of Alzheimer's disease by peripheral administration of agents with an affinity to beta-amyloid. $J$ Neurosci $23: 29-33$.

7. Biscaro B, Lindvall O, Hock C, Ekdahl CT, Nitsch RM, et al. (2009) Abeta immunotherapy protects morphology and survival of adult-born neurons in doubly transgenic APP/PS1 mice. J Neurosci 29: 14108-14119.

8. Sutcliffe JG, Hedlund PB, Thomas EA, Bloom FE, Hilbush BS, et al. (2011) Periphera reduction of $\beta$-amyloid is sufficient to reduce brain $\beta$-amyloid: implications for Alzheimer's disease. J Neurosci Res 89: 808-814.

9. Re F, Gregori M, Masserini M (2012) Nanotechnology for neurodegenerative disorders. Maturitas 73: 45-51.

10. Balducci C, Mancini S, Minniti S, La Vitola P, Zotti M, et al. (2014) Multifunctional liposomes reduce brain $\beta$-amyloid burden and ameliorate memory impairment in Alzheimer's disease mouse models. J Neurosci 34: 14022-14031.

11. Eisele YS, Monteiro C, Fearns C, Encalada SE, Wiseman RL, et al. (2015) Targeting protein aggregation for the treatment of degenerative diseases. Nat Rev Drug Discov 14: 759-780.

12. Oertel W, Schulz JB (2016) Current and experimental treatments of Parkinson disease A guide for neuroscientists. J Neurochem 139 Suppl 1: 325-337.

13. Wagner J, Ryazanov S, Leonov A, Levin J, Shi S, et al. (2013) Anle138b: a novel 
oligomer modulator for disease-modifying therapy of neurodegenerative diseases such as prion and Parkinson's disease. Acta Neuropathol 125: 795-813.

14. Levin J, Schmidt F, Boehm C, Prix C, Bötzel K, et al. (2014) The oligomer modulator anle138b inhibits disease progression in a Parkinson mouse model even with treatment started after disease onset. Acta Neuropathol 127: 779-780.

15. El-Agnaf OM, Paleologou KE, Greer B, Abogrein AM, King JE, et al. (2004) A strategy for designing inhibitors of alpha-synuclein aggregation and toxicity as a novel treatment for Parkinson's disease and related disorders. FASEB J 18: 1315-1317.

16. Madine J, Doig AJ, Middleton DA (2008) Design of an N-methylated peptide inhibitor of alpha-synuclein aggregation guided by solid-state NMR. J Am Chem Soc 130: 78737881.

17. Cheruvara H, Baume VL, Kad NM, Mason JM (2015) Intracellular screening of a peptide library to derive a potent peptide inhibitor of $\alpha$-synuclein aggregation. $J$ Biol Chem 290: 7426-7435.

18. Ruzza P, Gazziero M, Marchi MD, Massalongo G, Marchiani A, et al. (2015) Peptides as modulators of $\alpha$-synuclein aggregation. Protein Pept Lett 22: 354-361.

19. Zhu M, Rajamani S, Kaylor J, Han S, Zhou F, et al. (2004) The flavonoid baicalein inhibits fibrillation of alpha-synuclein and disaggregates existing fibrils. $J$ Biol Chem 279: $26846-26857$

20. Bieschke J, Russ J, Friedrich RP, Ehrnhoefer DE, Wobst H, et al. (2010) EGCG remodels mature alpha-synuclein and amyloid-beta fibrils and reduces cellular toxicity. Proc Natl Acad Sci U S A 107: 7710-7715.

21. Xu Y, Zhang Y, Quan Z, Wong W, Guo J, et al. (2016) Epigallocatechin Gallate (EGCG) Inhibits Alpha-Synuclein Aggregation: A Potential Agent for Parkinson's Disease. Neurochem Res 41: 2788-2796.

22. Caruana M, Hogen T, Levin J, Hillmer A, Giese A, et al. (2011) Inhibition and disaggregation of $\alpha$-synuclein oligomers by natural polyphenolic compounds. FEBS Lett 585: 1113-1120.

23. Tellone E, Galtieri A, Russo A, Giardina B, Ficarra S (2015) Resveratrol: A Focus on Several Neurodegenerative Diseases. Oxid Med Cell Longev 2015: 392169.

24. Jha NN, Ghosh D, Das S, Anoop A, Jacob RS, et al. (2016) Effect of curcumin analogs on $\alpha$-synuclein aggregation and cytotoxicity. Sci Rep 6: 28511.

25. Lotia M, Jankovic J (2016) New and emerging medical therapies in Parkinson's disease. Expert Opin Pharmacother 17: 895-909.

26. Mandler M, Valera E, Rockenstein E, Weninger H, Patrick C, et al. (2014) Nextgeneration active immunization approach for synucleinopathies: implications for Parkinson's disease clinical trials. Acta Neuropathol 127: 861-879.

27. Rutherford NJ, Brooks M, Giasson BI (2016) Novel antibodies to phosphorylated $\alpha$-synuclein serine 129 and NFL serine 473 demonstrate the close molecular homology of these epitopes. Acta Neuropathol Commun 4: 80.

28. Oueslati A (2016) Implication of Alpha-Synuclein Phosphorylation at S129 in Synucleinopathies: What Have We Learned in the Last Decade? J Parkinsons Dis 6: 39-51.

29. Wischik CM, Harrington CR, Storey JM (2014) Tau-aggregation inhibitor therapy for Alzheimer's disease. Biochem Pharmacol 88: 529-539.

30. Panza F, Solfrizzi V, Seripa D, Imbimbo BP, Lozupone M, et al. (2016) Tau-Centric Targets and Drugs in Clinical Development for the Treatment of Alzheimer's Disease. Biomed Res Int 2016: 3245935.

31. Wobst HJ, Sharma A, Diamond MI, Wanker EE, Bieschke J (2015) The green tea polyphenol (-)-epigallocatechin gallate prevents the aggregation of tau protein into toxic oligomers at substoichiometric ratios. FEBS Lett 589: 77-83.

32. Taniguchi S, Suzuki N, Masuda M, Hisanaga S, Iwatsubo T, et al. (2005) Inhibition of heparin-induced tau filament formation by phenothiazines, polyphenols, and porphyrins. J Biol Chem 280: 7614-7623.

33. Bulic B, Pickhardt M, Mandelkow EM, Mandelkow E (2010) Tau protein and tau aggregation inhibitors. Neuropharmacology 59: 276-289.

34. Cisek K, Cooper GL, Huseby CJ, Kuret J (2014) Structure and mechanism of action of tau aggregation inhibitors. Curr Alzheimer Res 11: 918-927.

35. Hampel H, Schneider LS, Giacobini E, Kivipelto M, Sindi S, et al. (2015) Advances in the therapy of Alzheimer's disease: targeting amyloid beta and tau and perspectives for the future. Expert Rev Neurother 15: 83-105.

36. Wischik CM, Lai RYK, Harrington CR (1997) Modelling prion-like processing of tau protein in Alzheimer's disease for pharmaceutical development. In: Avila J, Brandt R, Kosik KS, editors Microtubule-associated proteins: modifications in disease. Amsterdam: Harwood Academic Publishers 1: 185-241.

37. Wischik CM, Harrington CR, Storey JM (2014) Tau-aggregation inhibitor therapy for Alzheimer's disease. Biochem Pharmacol 88: 529-539.

38. Okuda M, Hijikuro I, Fujita Y, Wu X, Nakayama S, et al. (2015) PE859, a novel tau aggregation inhibitor, reduces aggregated tau and prevents onset and progression of neural dysfunction in vivo. PLoS One 10: 0117511.

39. Soeda Y, Yoshikawa M, Almeida OF, Sumioka A, Maeda S, et al. (2015) Toxic tau oligomer formation blocked by capping of cysteine residues with 1,2-dihydroxybenzene groups. Nat Commun 6: 10216.

40. Kim JH, Kim E, Choi WH, Lee J, Lee JH, et al. (2016) Inhibitory RNA Aptamers of Tau Oligomerization and Their Neuroprotective Roles against Proteotoxic Stress. Mol Pharm 13: 2039-2048.

41. Mohamed T, Shakeri A, Rao PP (2016) Amyloid cascade in Alzheimer's disease: Recent advances in medicinal chemistry. Eur J Med Chem 113: 258-272.

42. Cheng B, Gong H, Xiao H, Petersen RB, Zheng L, et al. (2013) Inhibiting toxic aggregation of amyloidogenic proteins: a therapeutic strategy for protein misfolding diseases. Biochim Biophys Acta 1830: 4860-4871.

43. Jiang P, Li W, Shea JE, Mu Y (2011) Resveratrol inhibits the formation of multiplelayered $\beta$-sheet oligomers of the human islet amyloid polypeptide segment 22-27. Biophys $J$ 100: 1550-558

44. Ono K, Li L, Takamura Y, Yoshiike Y, Zhu L, et al. (2012) Phenolic compounds prevent amyloid $\beta$-protein oligomerization and synaptic dysfunction by site-specific binding. $J$ Biol Chem 287: 14631-14643.

45. Yang F, Lim GP, Begum AN, Ubeda OJ, Simmons MR, et al. (2005) Curcumin inhibits formation of amyloid beta oligomers and fibrils, binds plaques, and reduces amyloid in vivo. J Biol Chem 280: 5892-5901

46. Sharma B, Paul S (2016) Action of Caffeine as an Amyloid Inhibitor in the Aggregation of Aß16-22 Peptides. J Phys Chem B 120: 9019-9033.

47. Hori Y, Takeda S, Cho H, Wegmann S, Shoup TM, et al. (2015) A Food and Drug Administration-approved asthma therapeutic agent impacts amyloid $\beta$ in the brain in a transgenic model of Alzheimer disease. J Biol Chem 290: 1966-1978.

48. Landau M, Sawaya MR, Faull KF, Laganowsky A, Jiang L, et al. (2011) Towards a pharmacophore for amyloid. PLoS Biol 9: e1001080.

49. Arai T, Sasaki D, Araya T, Sato T, Sohma Y, et al. (2014) A cyclic KLVFF-derived peptide aggregation inhibitor induces the formation of less-toxic off-pathway amyloid- $\beta$ oligomers. Chembiochem 15: 2577-2583.

50. López LC, Dos-Reis S, Espargaró A, Carrodeguas JA, Maddelein ML, et al. (2012) Discovery of novel inhibitors of amyloid $\beta$-peptide 1-42 aggregation. J Med Chem 55: 9521-9530.

51. Choi SH, Olabarrieta M, Lopez OL, Maruca V, Dekosky ST, et al. (2012) Gray matter atrophy associated with extrapyramidal signs in the Lewy body variant of Alzheimer's disease. J Alzheimers Dis 32: 1043-1049.

52. Lemere CA, Masliah E (2010) Can Alzheimer disease be prevented by amyloid-beta immunotherapy?. Nat Rev Neurol 6: 108-119.

53. Adolfsson O, Pihlgren M, Toni N, Varisco Y, Buccarello AL, et al. (2012) An effectorreduced anti- $\beta$-amyloid $(A \beta)$ antibody with unique a $\beta$ binding properties promotes neuroprotection and glial engulfment of A $\beta$. J Neurosci 32: 9677-9689.

54. Bohrmann B, Baumann K, Benz J, Gerber F, Huber W, et al. (2012) Gantenerumab: a novel human anti-Abeta antibody demonstrates sustained cerebral amyloid-beta binding and elicits cell-mediated removal of human amyloid-beta. $J$ Alzheimers Dis 28: 49-69.

55. Doody RS, Thomas RG, Farlow M, Iwatsubo T, Vellas B, et al. (2014) Phase 3 trials of solanezumab for mild-to-moderate Alzheimer's disease. N Engl J Med 370: 311-321.

56. Giacobini E, Gold G (2013) Alzheimer disease therapy--moving from amyloid- $\beta$ to tau Nat Rev Neurol 9: 677-686.

57. Guillozet AL, Weintraub S, Mash DC, Mesulam MM (2003) Neurofibrillary tangles, amyloid, and memory in aging and mild cognitive impairment. Arch Neurol 60: 729736

58. Siemers ER, Sundell KL, Carlson C, Case M, Sethuraman G, et al. (2016) Phase 3 solanezumab trials: Secondary outcomes in mild Alzheimer's disease patients. Alzheimers Dement 12: 110-120. 
59. Sperling RA, Jack CR, Aisen PS (2011) Testing the right target and right drug at the right stage. Sci Transl Med 3: $111 \mathrm{~cm} 33$.

60. Clinton LK, Blurton-Jones M, Myczek K, Trojanowski JQ, LaFerla FM, et al. (2010) Synergistic Interactions between Abeta, tau, and alpha-synuclein: acceleration of neuropathology and cognitive decline. $J$ Neurosci 30: 7281-7289.
61. Larson ME, Sherman MA, Greimel S, Kuskowski M, Schneider JA, et al. (2012) Soluble $\alpha$-synuclein is a novel modulator of Alzheimer's disease pathophysiology. $J$ Neurosci 32: 10253-10266.

62. Umeda T, Maekawa S, Kimura T, Takashima A, Tomiyama T, et al. (2014) Neurofibrillary tangle formation by introducing wild-type human tau into APP transgenic mice. Acta Neuropathol 127: 685-698.

Copyright: $\odot 2017$ Pietrobono D. This is an open-access article distributed under the terms of the Creative Commons Attribution License, which permits unrestricted use, distribution, and reproduction in any medium, provided the original author and source are credited. 